Article

\title{
Trends and Research Issues of Augmented Reality Studies in Architectural and Civil Engineering Education-A Review of Academic Journal Publications
}

\author{
Pei-Huang Diao $(\mathbb{D}$ and Naai-Jung Shih * $*$ \\ Department of Architecture, National Taiwan University of Science and Technology, 43, Section 4, Keelung Road, \\ Taipei 106, Taiwan; diaoph@msn.cn \\ * Correspondence: shihnj@mail.ntust.edu.tw; Tel.: +886-02-2737-6718.
}

Received: 21 March 2019; Accepted: 2 May 2019; Published: 4 May 2019

check for updates

Featured Application: 1. A systematic review of literature was conducted concerning augmented reality (AR) in architectural and civil engineering education. 2. AR is discovered to possess a wide range of applications in general pedagogies and domain-specific learning. 3. The advantages and challenges of AR in this field are reported. 4. Analysis was performed based on fundamental information, application domains, AR development tools, system types, teaching devices, teaching methods, learning strategies, and research methods. 5. Discussions and suggestions were made regarding the advantages in pedagogies and education, the challenges to systems and curriculums, the selection of suitable systems, and the emerging trends of AR and building information modeling (BIM) combined. 6. Collaboration should occur among different roles. The trends and research have become an integrated and collaboration issue, that should be conducted interactively with pedagogical findings and resources integrated across different parties.

\begin{abstract}
Architectural and civil engineering (ACE) education is inextricably connected to real-world practice. The application of augmented reality (AR) technology can help to establish a link between virtual and real-world information for students. Studies of applying AR in ACE education have increased annually, and numerous research have indicated that AR possesses immense application potential. To address and analyze pertinent research issues, published studies in the Scopus database were explored, and revealed that problems persist and are worthy of attention, such as the selection of system types and devices, the application of research methods, and appropriate learning strategies and teaching methods. Courses with objective grading standards should be given priority in AR experimental courses for a meticulous investigation of AR influence on students' learning outcomes and ultimately improvement of classroom quality. Suitable types of AR systems should be selected based on course content, prior to the design and development of the system. It is recommended to develop markerless systems for a larger application range to benefit students with additional convenience. Systems can also be accompanied by functions, such as instant online assessments, synchronized assessments, and exchange capabilities to assist learning what has been taught and develop critical thinking abilities. The combination of AR and building information modeling (BIM) in architectural and civil practice, which has immense application potential, has become an emerging research trend. Collaboration between academics and practice should be enhanced with roles and knowledge of instructors, engineers, designers, and computer experts integrated for an optimal connection between general pedagogy and domain-specific learning. Teaching methods that emphasize "locations", as well as "roles", can be adopted in order to create a superior reality learning environment with diversified learning methods. The trends and research have become an integration and collaboration issue that should be performed interactively with pedagogical findings, and resources integrated across roles, fields, and university departments.
\end{abstract}


Keywords: augmented reality; architecture and civil engineering; interactive learning environments; teaching/learning strategies; pedagogical issues; mobile technology

\section{Introduction}

Architectural and civil engineering (ACE) education is a form of practice-based knowledge delivery, in which subjects are frequently related to the configuration and property of 3D objects. A construction, such as a building, bridge, or space is usually associated with component information, such as stress, dimension, materials, assembly, and construction. Building models have been used to define information from concept design, schematic design, detailed design, construction documentation, fabrication and assembly, to as-built. It has been a trend to apply different types of simulations to virtual models for pedagogy or practice needs, evaluations, practice rehearsals, training, and demonstrations of proposed solutions. Considering professional characteristics in linking the virtual design and the projected property in the real world, augmented reality (AR) is applied to fulfill educational and specialized practice needs.

In recent years, AR has sparked widespread attention and discussion in ACE. AR has been defined in a broad sense as "augmenting natural feedback to the operator with simulated cues" to a more restricted approach as "a transparent head-mounted display (HMD) allowing a participant's clear view of the real world" [1]. Overall, it aims for real and virtual objects in a real environment to be combined, registered, and interacted in real-time. The definition of AR was then gradually broadened to apply particular displays and sensors for auditory, tactile, and olfactory modalities [2,3]. For instance, Irizarry et al. [4] proposed a mobile augmented reality method to increase efficiency and productivity in facility management. Hou et al. [5] developed an animated AR system for guided assembly tasks to reduce errors and to augment operational efficiency. Koch et al. [6] proposed a natural marker-based AR framework that can digitally support facility operators in performing daily on-site maintenance tasks. Meža et al. [7] used AR to promote users' understanding of project documentation in various stages of construction projects. In addition, Chi et al. [8] discussed trends in AR applications for architecture, engineering, construction, and facility management, anticipating that AR applications will be further utilized in ACE fields, and to augment productivity, safety, and efficiency.

The traditional tools of pen and paper have been replaced by building information modeling (BIM) software [7]. The main advantage of BIM is that it can keep tracking the operation of various projects in a building lifecycle, in order to enhance project productivity and improve communication efficiency among professional staff $[9,10]$. Some forward-thinking scholars have begun combining BIM and AR in architectural and civil practice, with the intention of further tapping into the potential of BIM. For instance, Park et al. [11] proposed a conceptual framework for proactive construction defect management using BIM and AR, to reduce and prevent defect occurrence during the construction process. The majority of studies predicted AR to become the optimal choice for expanding BIM concepts and methods. [12,13].

Part of traditional education has been conducted in laboratories with experiments in field practice to shorten the gap between classroom and real tasks, as one of the measurements in pedagogy. Typical observations should be made to check if knowledge is acquired, motivation is increased, and outcomes are improved. AR seems to constitute a portable laboratory that can be operated anytime or right next to the subject, in contrast to the hand-made modeling approach that must be performed in a specific location with large facilities.

With advancements in technology and support, the development of AR systems has become much easier. AR is being applied to education, and has led to impressive results [14-18]. Research on the use of AR in education has increased steadily and offers great insights into learning and teaching [19]. The employment of AR is attempted to improve classroom quality from kindergarten, elementary school, secondary school, to universities [20-22]. AR enables students to use 3D synthetic 
objects to augment visual perceptions of target systems or environments [23]. Numerous studies have also indicated that AR can assist students to better acquire classroom knowledge, improve learning outcomes, and boost motivation [24,25].

The emergence of AR has provided an opportunity to reform ACE education. Content in the ACE curriculum is closely linked to the real world, and creating stronger connections with industry is critical [26,27]. The most important characteristic of AR is its ability to link the virtual and real worlds [1-3]. Using AR can help students to establish connections of information between virtual worlds and real worlds more easily, and make abstract 2D knowledge and concepts in original courses more concrete [28]. Students' ability to understand and convert information between the virtual world and the real world is particularly critical in ACE learning processes. Students can inspect the 3D object from a variety of perspectives to enhance their comprehension [29]. The utilization of AR can also provide students with the opportunity to learn in the real world, which supersedes pedagogy that is confined to traditional classroom learning [30].

The research questions (RQ) of the current paper, concerning AR and ACE education, are presented in Table 1.

Table 1. Research questions concerning applying augmented reality (AR) in architectural and civil engineering (ACE) education.

\begin{tabular}{ll}
\hline RQ1 & What are the extant trends? In which courses is AR used more frequently? \\
\hline RQ2 & What are the AR system development programs? \\
\hline RQ3 & What are the common learning strategies, pedagogies, and research methods? \\
\hline RQ4 & What are the advantages and challenges? \\
\hline
\end{tabular}

\section{Research Methods}

Papers related to AR in ACE education and published prior to January 1, 2019 were searched, coded, and analyzed.

\subsection{Resources}

ACE education possesses domain characteristics under the special nature of engineering history and practice. Although AR has been applied in education, no systematic analysis has yet been performed. The development of an AR system can comprise computer science, medical science, and other fields in a collaborative manner of hardware and software system built-ups. To elucidate relevant trends and research issues, the selection of an appropriate database needs to be focused on this domain.

The review starts from selecting a specific database, which has a close relation to ACE education. An analysis is conducted for all of the published studies in the database to the end of December 31, 2018, with the purpose to understand research trends, advantages, and challenges. Scopus seems to be relatively more focused and related to ACE, with the world's largest abstract and citation database of peer-reviewed literature, including scientific journals, covering research topics across all scientific and technical disciplines. The database also aims to provide references and recommendations of journal papers for scholars in the future to enhance teaching effects and learning quality.

Journal papers were searched in the Scopus database and filtered through keywords in the paper title, abstract, or keywords list. The research questions were raised and transferred into coding schemes from basic information, systems, and challenges. Data analysis and discussion were also performed afterward. We selected 1299 papers based on certain keywords, including "augmented reality" and "architecture" or "building" or "engineering" or "construction", and "education" or "learning" or "teaching." Non-journal and non-ACE education related papers were removed. A total of 21 papers (see Appendix A) were in the final analysis list (Figure 1). 


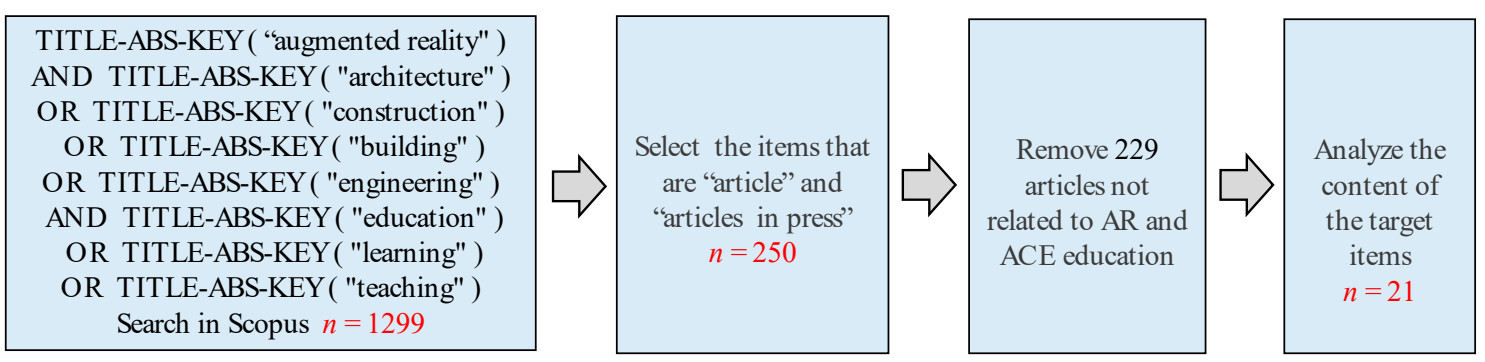

Figure 1. Scopus database searching steps.

Many AR-related researches contribute to ACE. The most important part of the review in the domain-specific field (i.e., ACE) is to ensure that high quality journal papers will be identified. A variety of combinations were employed to achieve this goal. In the early stage of search, very few journal papers were found in Scopus using both "architecture" and "civil engineering" as keywords. To avoid missing counts of papers, "civil engineering" was replaced by "engineering" with keywords "construction" and "building", and with an "or" search. Eventually, 21 papers were retrieved.

Over-emphasis of domain-specific studies may lead cross-domain contributions to be ignored. Although AR studies in different fields are equally important and influential, domain-specific studies, which have been applied with clear and defined results, would contribute meaningfully to ACE. In this study, the majority of core topics or courses in the department of architecture and civil engineering are closely related, such as construction method, structure system and analysis, building materials, computer graphics, 3D modeling, etc. This is why certain keywords, such as "urban" and "city", were excluded, along with numerous other important ones.

\subsection{Coding Schemes}

Coding schemes are methods of categorizing scientific data [31]. All articles were coded and analyzed according to the research questions $(\mathrm{RQ})$, and literature were referred in order to determine coding schemes $[19,27,32,33]$. The contents and coding schemes of the research questions (RQ) are classified into four types (Table 2). For example, in RQ2, it is necessary to separate marker and markerless systems, since the former seems to be evolved from the latter with many tasks simplified. The former can even be conducted by directly implanting a 3D model in an environment. It is important to note that application simplicity gains user support quickly.

Table 2. Reference and description of the coding scheme.

\begin{tabular}{|c|c|c|c|}
\hline & $N$ & Items & Coding Schemes \\
\hline \multirow[b]{2}{*}{ RQ1 } & 1 & Basic information & Author's country, region, and year \\
\hline & 2 & Application domains & $\begin{array}{l}\text { Fields or course directions for general pedagogy or } \\
\text { domain-specific learning }\end{array}$ \\
\hline \multirow{3}{*}{ RQ2 } & 3 & Development tools & Tools or platforms \\
\hline & 4 & System types & $\begin{array}{l}\text { Marker-based or markerless types by triggering mechanisms } \\
\text { in presenting virtual objects }\end{array}$ \\
\hline & 5 & Device types & Smartphones, tablets, or laptops \\
\hline \multirow{3}{*}{ RQ3 } & 6 & Teaching methods & Emphasis of roles, locations, or tasks \\
\hline & 7 & Learning strategies & $\begin{array}{l}\text { Peer assessment, issue-based learning, synchronous sharing, } \\
\text { or project-based learning [32] }\end{array}$ \\
\hline & 8 & Research methods & $\begin{array}{l}\text { Experimental design method, questionnaire survey, } \\
\text { qualitative research method, system development, and } \\
\text { document analysis [34] }\end{array}$ \\
\hline \multirow{2}{*}{ RQ4 } & 9 & Advantages & In general pedagogy and domain-specific learning \\
\hline & 10 & Challenges & In system problems and course issues \\
\hline
\end{tabular}




\section{Research Analysis}

Analysis was performed on the AR-related coding schemes, based on fundamental information, application domains, development tools, system types, teaching devices, teaching methods, learning strategies, and research methods. For example, the form of learning subject can be in 3D virtual models or text-based notational explanations using markers or markerless schemas, in a location in the field or in a classroom, with a specific supporting environment of hardware and software.

\subsection{Basic Information}

Countries and regions of the first author, who applied AR in ACE educational research, are recorded. The top three countries and regions among the papers are Spain, the United States, and Taiwan (Figure 2). Relevant studies have been published since 2011, indicating that the overall number of papers has increased steadily (Figure 3).

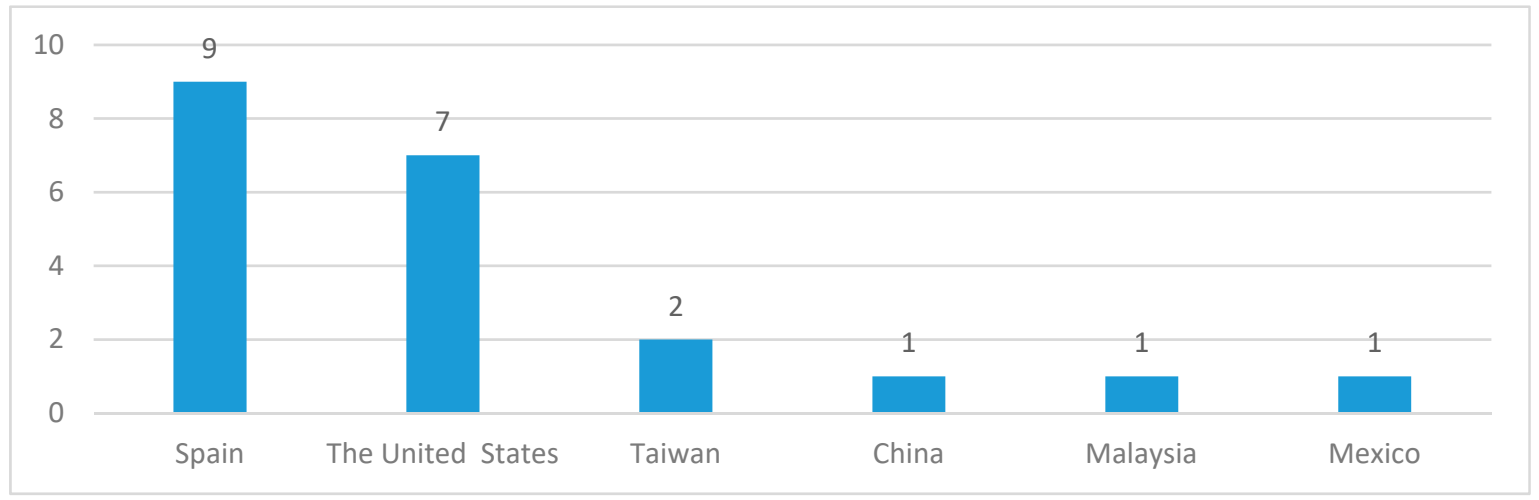

Figure 2. The number of studies published by country and regions.

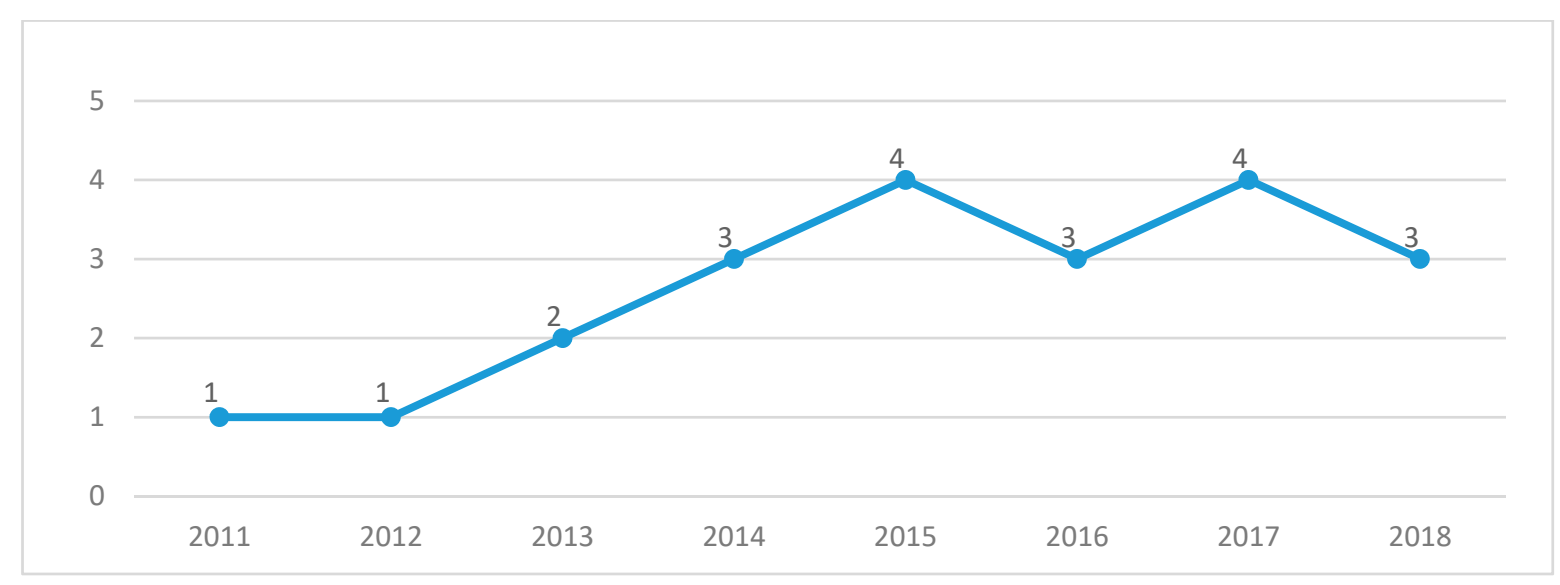

Figure 3. The number of studies published by year.

\subsection{Application Domains}

AR is widely applied in ACE education for general (50\%) and domain-specific learning (50\%) (Figure 4). Related papers include an overview of academic performance using AR, and discuss how this type of technology can improve students' 3D spatial skills in tools, geometries, representations, and graphics [24,35]. By using AR to understand domain-specific contents of textbooks and assignments, students can reduce the cognitive gap between academics and practice in construction, estimation, structure analysis, exterior wall design, building design, and assembly [28,36]. The most applied course is "informatics tools," followed by "construction methods and materials." "Informatics tool" refers to a general computer tool, such as 3D modeling. Students can take this class to create 3D models for a real representation of an object or a space to improve a student's 3D spatial skills. The goal of 
the "geometry course" is to learn how to develop skills to understand visual perception and spatial expression $[37,38]$.
- General application of AR knowledge: Informatics tool Geometry course Technical assessment Representation system Engineering graphics Graphical and spatial

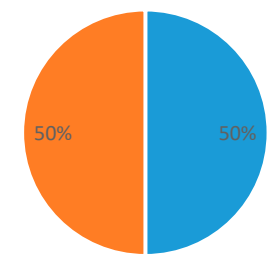

- Domain-specified application of AR knowledge: Construction methods and materials Exterior wall designs

History of western architecture

Primary structure analysis

Building design and assembly

Estimating course

Figure 4. The percentage of application domains.

Domain-specified or general applications of AR knowledge vary in emphasis on a course or computer skill. The former relates to a domain that applies AR technology, in which a course number is usually given under a common name, such as "Construction methods and materials", as part of the "interface" using AR to deliver knowledge. The latter relates to a course that supports other courses, such as "3D modeling", as a computer-related skill without a specific application goal. In general, the latter is usually given in a computer science department related to hardware, interface, or computer graphics. A similar course can also be offered by a subject's department for more direct learning support.

The terms used to name a course can differ by country, university, and department. In general, the major part of a course is similar. The application of AR across departments can be related or referred to as a fundamental requirement for students to enhance their computer knowledge in general, or as a skill or tool learned without a specific course in mind, such as an informatics tool, geometry course, representation system, engineering graphics knowledge, graphical and spatial applications, etc. It can also be given as an assignment in which a domain-specific subject can be applied and learned, such as construction methods and materials, exterior wall design, history of western architecture, primary structure analysis, building design and assembly, etc.

\subsection{Development Tools}

AR development involves platforms, interfaces, and tools. Platforms can be smartphone-based or PC-based, mobile-based or station-based, wireless or wired, or an HMD or hand-held device. Interfaces can be hands-on learning or visual enhancement manipulation. The former includes the manipulation of structural details. The latter comprises manipulation of instruction or texts. Tools can be off-the-shelf packages or software development kit (SDK) at different levels of course involvement for general knowledge/experience delivery or customized subject learning, developed by instructors or supporting laboratories. The nature of tools can be used for enhanced fundamental course learning or general 3D operation. Related interfaces can be either text or with assembly, movement, or rotation made as a whole or part of a set of 3D geometries.

16 papers, except for five unspecified ones, used existing AR tools or platforms. AR-media ${ }^{\mathrm{TM}}$, ARToolKit ${ }^{\circledR}$, and Junaio ${ }^{\circledR}$ are applied most frequently (Figure 5). AR-media ${ }^{\mathrm{TM}}$ is widely applied, and can be combined with many types of 3D modeling software. ARToolKit ${ }^{\circledR}$ is the world's earliest AR open source software. Junaio ${ }^{\circledR}$ can be utilized on different system platforms. 


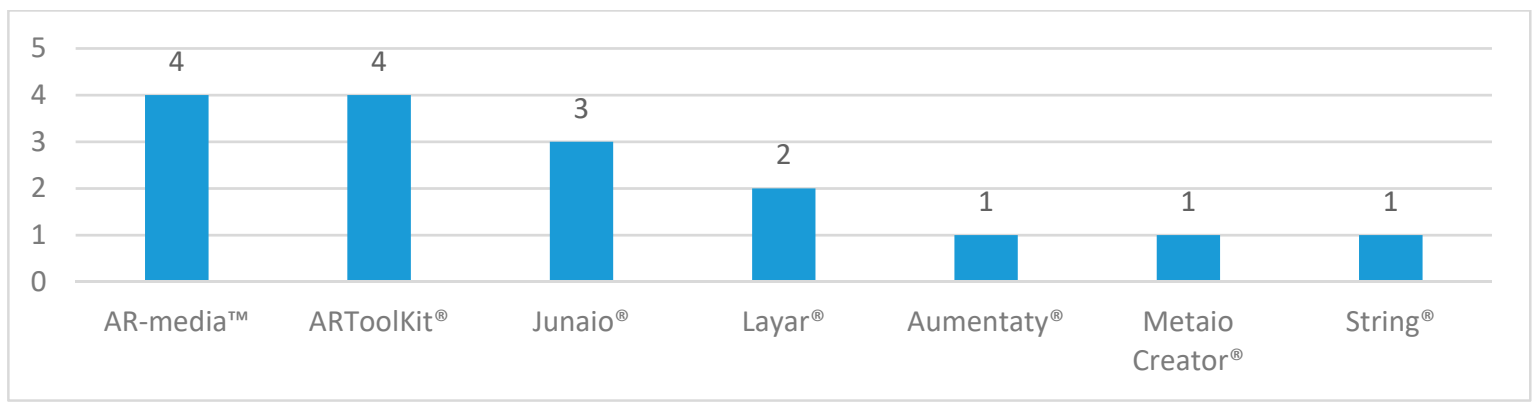

Figure 5. The number of adopted development tools in AR studies for ACE education.

\subsection{System Types}

A user normally needs to inspect an object from different elevations or angles in $360 \times 360$ degrees. Virtual objects must be tracked in order to be displayed in a correct orientation. When a virtual object is superimposed in a physical world, correct relative location should be maintained without drifting after a user moves. The system actually tracks the configuration of the real environment to ensure that the virtual object is placed accurately or in a correct relative translation to the former location. In contrast, a GPS or a compass can hardly achieve this in a precise manner.

Marker-based AR and markerless AR constitute two major categories of AR [27]. Markers are 2D patterns or symbols that can be recognized by a computer system [28]. Marker-based AR needs to identify corresponding markers, so that presupposed information can be presented. The marker system requires an image or $2 \mathrm{D}$ barcode to achieve registration and tracking. A difference exists between the simulated scenario and the real one. An image-based marker also separates students from learning a real scenario, since a printed marker, which has to be placed appropriately for registration, does not necessarily appear in a real site. Pasting and tearing markers on the surface, which may cause damage to an artifact, are prohibited by law while working with items with a national heritage designation. Although a real scene can be used as a marker in a markerless approach, difficulty may be encountered upon deviations made to the preset view or insufficient lighting conditions.

Markerless AR does not require marker registration, and tracking is more robust in enabling the realization of mobile AR. This approach is made by matching a model with the geometries of a subject or an environment to be registered for correct alignment. 3D attributes of the geometry, which can be categorized as a type of marker, can fit in a real physical scenario to reduce the difference from reality for easier student adaption in the future.

Figure 6 shows the distribution of the types adopted in each study. Fifteen papers adopted marker-based AR [24,39] and three papers used markerless AR [35,40]. Three papers did not develop or specify systems [25,38].

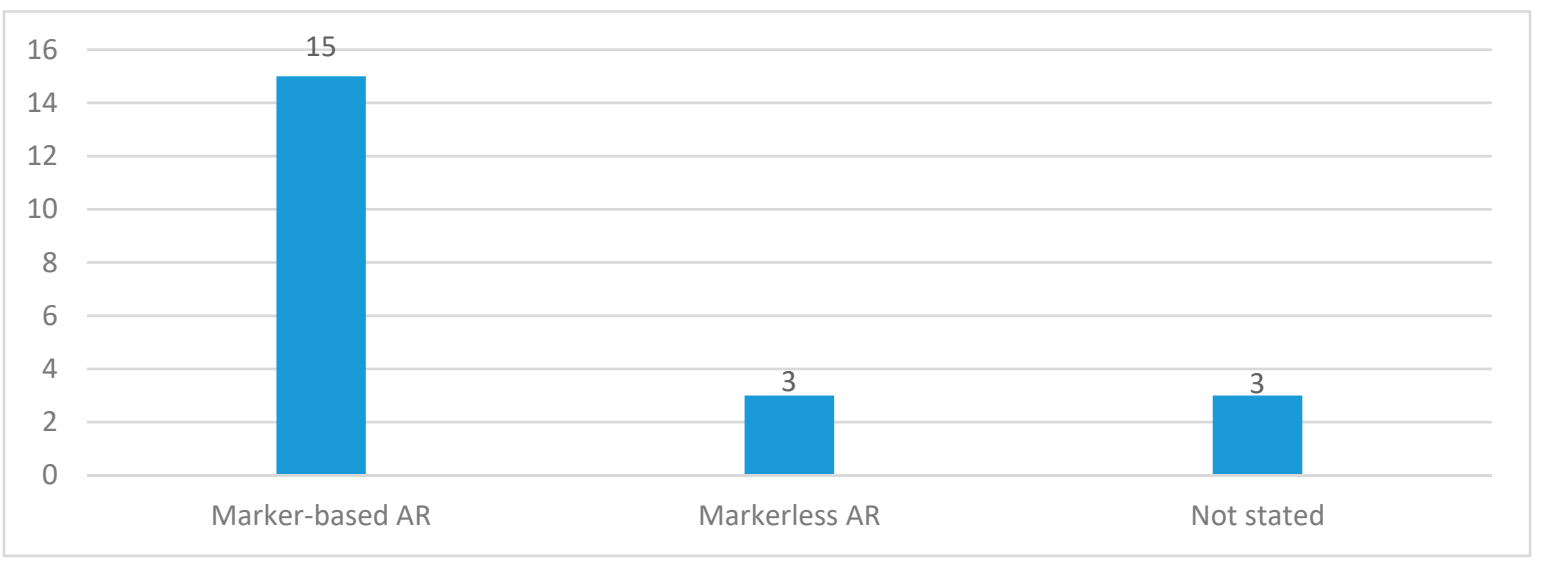

Figure 6. The number of studies in each applied AR system. 


\subsection{Teaching Devices}

A mobile device is usually equipped with a very sensitive gyroscope to record user movement in order to provide a correct relative location between the real environment and the virtual object. Different technologies, such as visual inertial odometry (VIO), are also applied as a simultaneous localization and mapping (SLAM) function to track locations in real-time.

Most papers adopted mobile devices to install AR applications (67\%) [36,41] (Figure 7 left). Smartphones were adopted most (57\%), followed by tablets (Figure 7 right). Only one paper used a head-mounted display (HMD) [28].
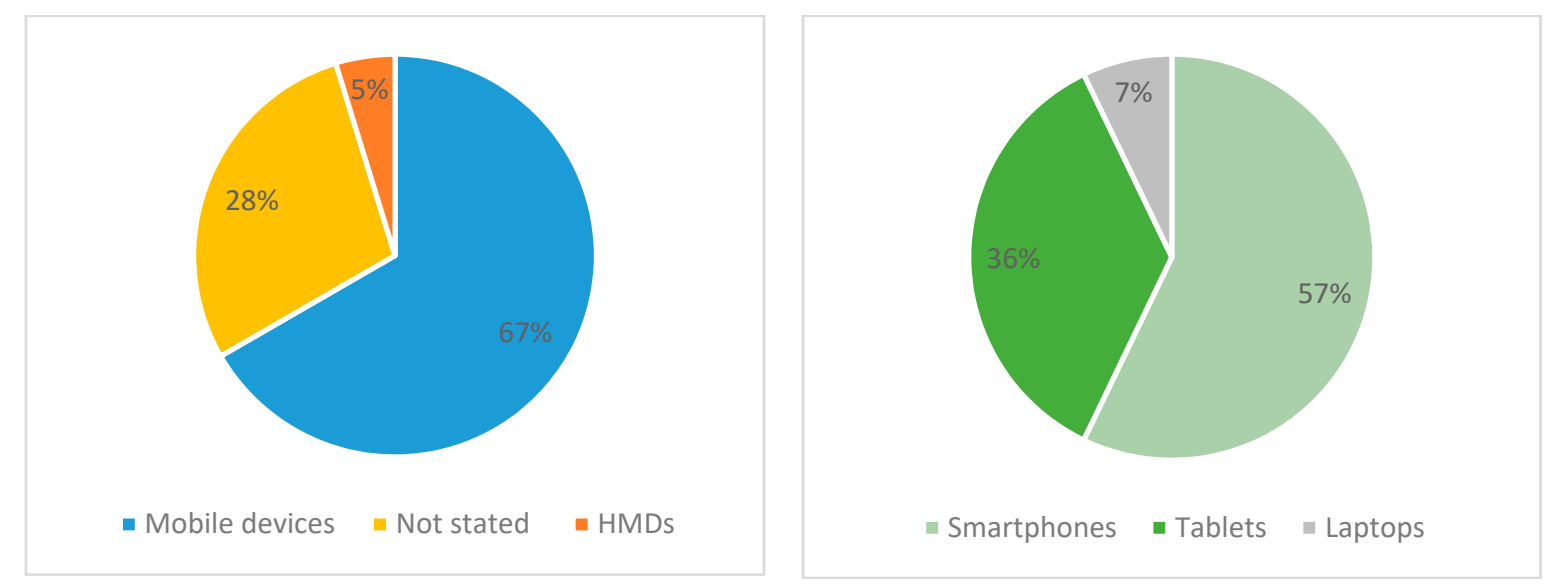

Figure 7. The percentage of applied AR teaching devices. Left: device type, Right: mobile device type.

\subsection{Teaching Methods}

The essential characteristics of teaching methods comprise placing students in a learning scenario similar to that encountered in professional practice, in which roles, locations, and tasks constitute the three basic parts to describe a job. For example, students may act like a job inspector, go to a construction site, or perform an equipment check. Moreover, three types of AR teaching methods exist in ACE education [42]. The first type is "emphasizes the roles", in which students play different roles within an AR system and interact with each other through communication and discussion. The core feature is to emphasize interactions between students. The second type is "emphasizes the locations", in which students leave the traditional classroom and go to a given location outdoors to use AR to complete their studies [41,43]. In the third type "emphasizes the task", students use AR to complete learning tasks in the form of a game or direct communication. Unlike the other two teaching types, there is no grouping or classification of students into different roles, and most of the studies were conducted indoors [24,37].

Fourteen papers adopted the type, emphasize the task (Figure 8). Four papers adopted the type, emphasize the locations. The number of papers that adopted the type, emphasizes the roles, was zero, because the grading applied for tasks and locations was not found for roles. The remaining three papers, which are either literature reviews or not categorized, are classified as "others." The number of papers that used the emphasize-the-task teaching method increased from 2011 to 2018 (Figure 9), while the number of other teaching methods remained relatively stable. 


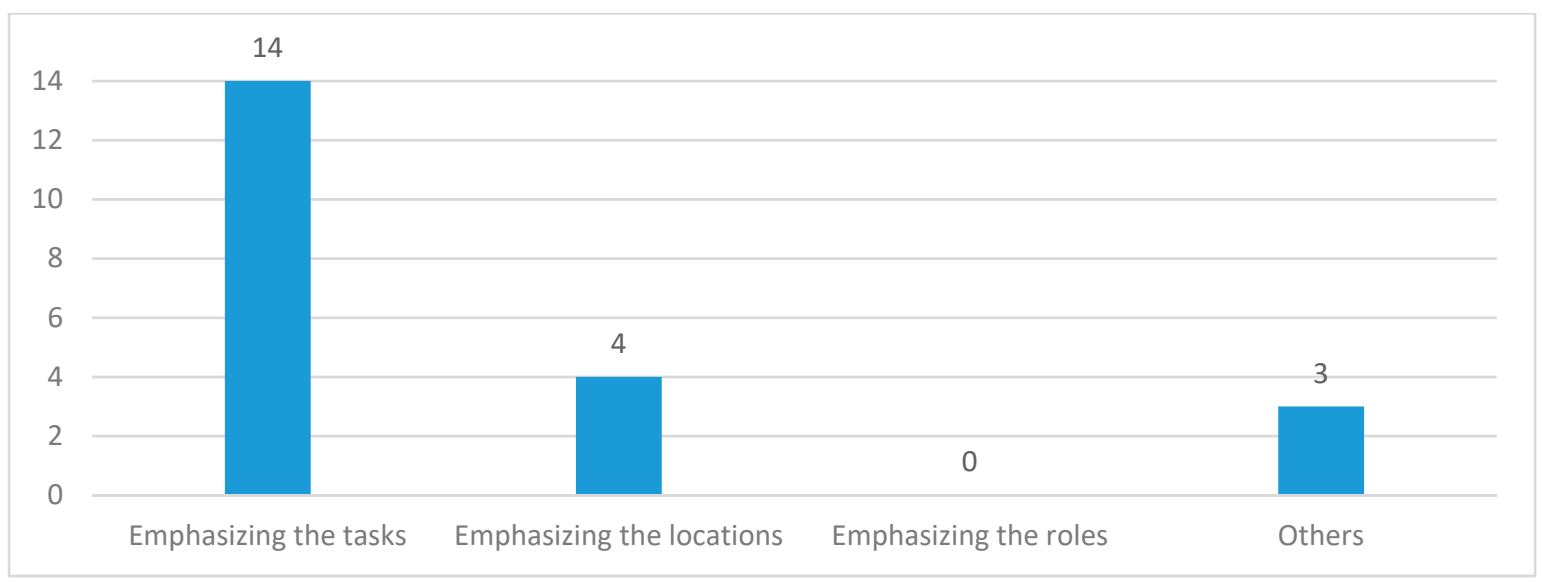

Figure 8. The number of studies for each teaching method.

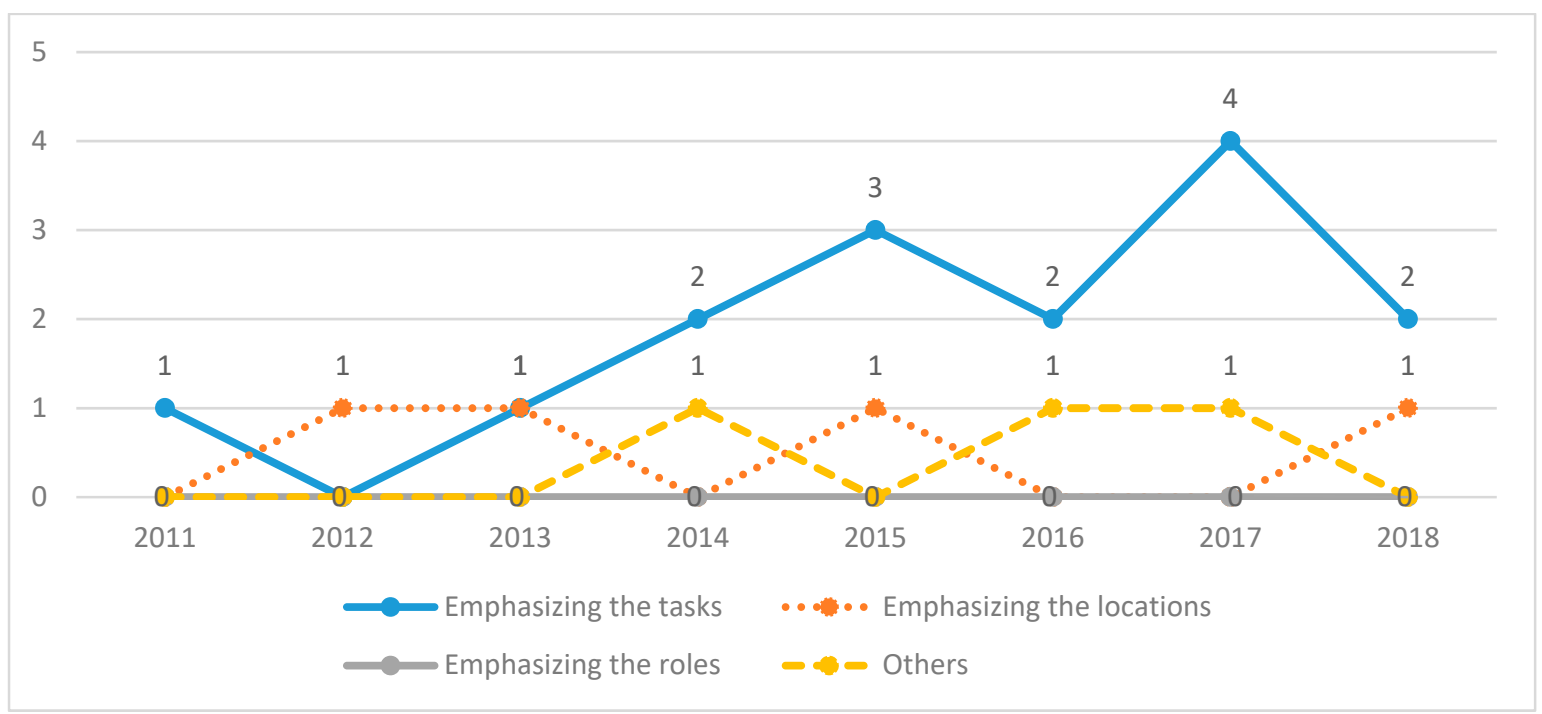

Figure 9. The number of AR teaching methods by year.

\subsection{Learning Strategies}

Project-based learning (79\%) is the most common learning strategy used by researchers (Figure 10). Teachers instruct students to use AR to complete their projects, presentations, and reports involving 3D virtual models and physical building models $[17,44]$. The second most-used method is peer assessment $(11 \%)$, in which students rate AR works created by other students based on evaluation criteria provided by teachers. A relevant AR case is the curtain wall design of campus buildings, for which students must comment on each other's designs [35]. The other two less-often adopted learning strategies are issue-based learning and synchronous sharing, in which students discuss an issue related to the learning content or interact through AR in a timely manner involving discussion and sharing [39,40]. The number of papers that adopted project-based learning gradually increased from 2011 to 2018 (Figure 11). These four learning strategies are defined as peer assessment, synchronous sharing, issue-based learning, and project-based learning, respectively [45]. 


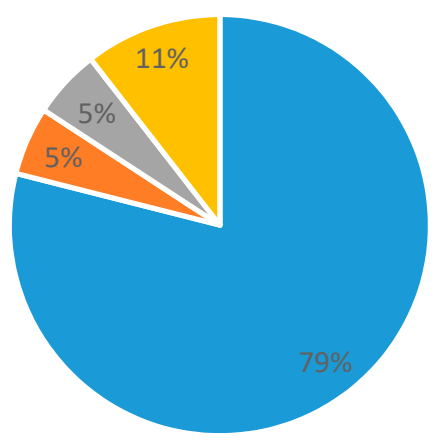

- Project-based learning = Synchronous sharing = Issue-based learning = Peer assessment

Figure 10. The percentage of learning strategies.

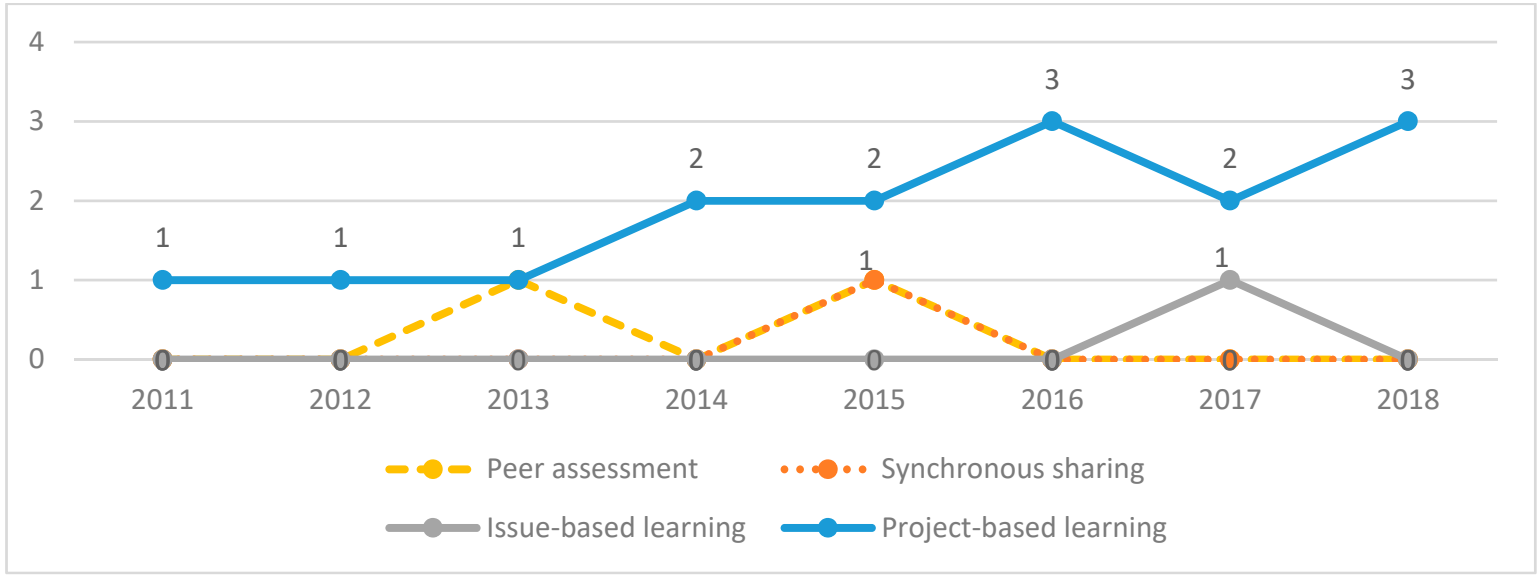

Figure 11. The number of papers published in learning strategies by year.

\subsection{Research Methods}

Research methods of AR in ACE education are three-fold: The experimental design method, the document analysis method, and the system development method. Figure 12 shows that $86 \%$ of the 21 chosen papers adopted the experimental design method. Specifically, students were divided into experimental groups and control groups in AR courses to discuss the benefits and influence of AR $[24,34,37,40]$. Two papers (9\%) adopted the document analysis method in multiple AR applications, $[25,46]$. Only one paper $(5 \%)$ adopted system development to explore the framework in AR system development [43]. Figure 13 shows that the mainstream research method between 2011 and 2018 is still the experimental design method, and the number of related research projects increases by year.

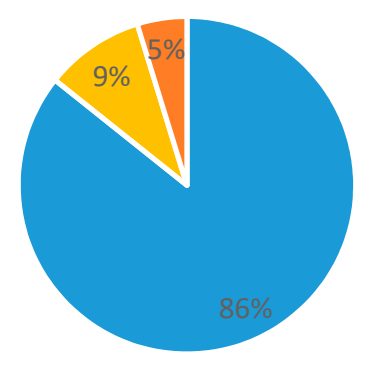

- Experimental design method $\quad$ Document analysis $\quad$ System development

Figure 12. The percentage of three research methods. 


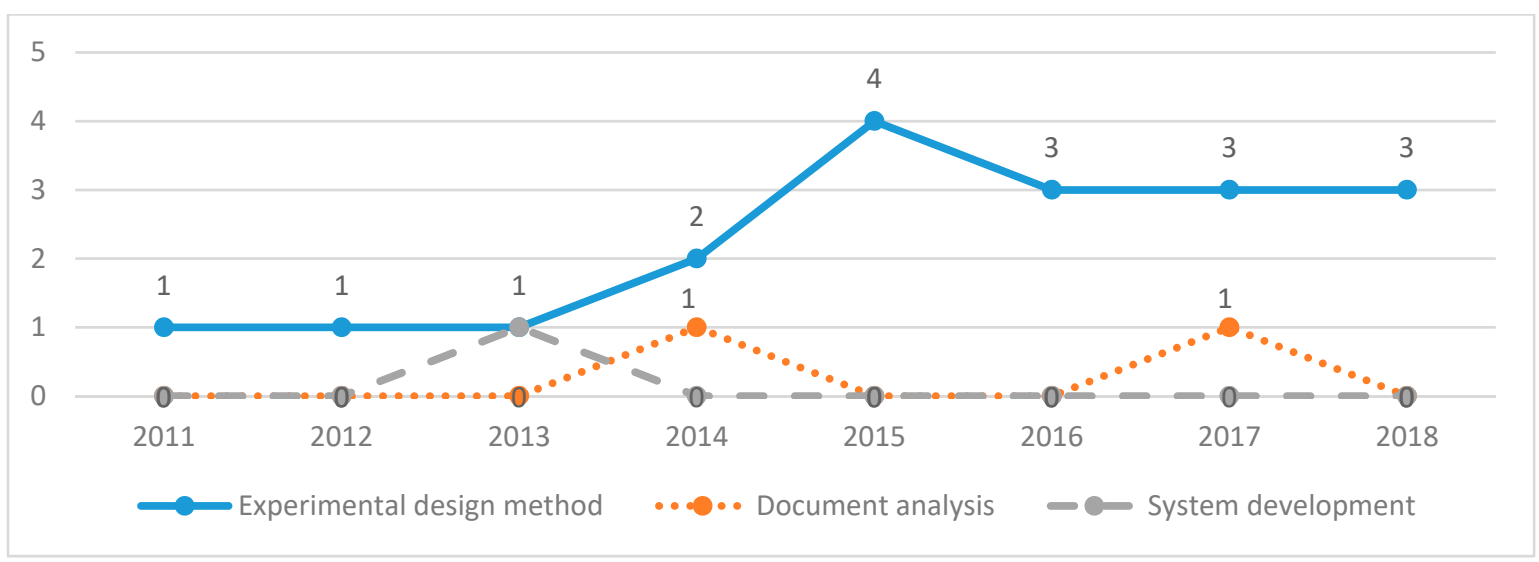

Figure 13. The number of papers published in research methods by year.

\section{Discussions and Suggestions}

AR is usually considered as a new type of interface, in which knowledge is conveyed to users in a visual or hands-on experience. The interaction or the content is still determined by the design of instructors or experts in a specific domain. The efficiency in delivering knowledge has been improved, in general, and created a unique teaching and learning experience. Suggestions are made, and a discussion is conducted regarding the research questions listed in Table 1.

\subsection{Promoting the Advantages in General Pedagogies and Domain-Specific Learning}

The advantages of using AR in an ACE education curriculum are related to general pedagogies and domain-specific learning, with the former mentioned the most. The most frequently cited categories are the improvement of a student's interest in learning, performance, and motivation $[24,44,46]$ (Table 3). The most-mentioned domain-specific learning is that the students increased in graphic competencies and spatial skills [47]. The advantages illustrate great potential in combining the attributes of the physical with designated information with reasonable arrangements or a direct manipulation without needing to consider where to paste the marker. AR is helpful in completing projects, presentations, and reports involving 3D virtual models and physical building models in a unique user interface.

Table 3. The advantages of AR in ACE education curriculums.

\begin{tabular}{cccc}
\hline Inductive Categories & Sub-Categories & Quantity & Sample Research \\
\hline & Improve students' learning interest & 7 & {$[39]$} \\
\cline { 2 - 4 } General pedagogies & Improve students' academic performance. & 6 & {$[24]$} \\
\cline { 2 - 4 } & Motivate students more & 4 & {$[47]$} \\
\cline { 2 - 4 } & Satisfaction of students with the course & 4 & {$[48]$} \\
\cline { 2 - 4 } & Effective tool in traditional pedagogical settings & 4 & {$[36]$} \\
\cline { 2 - 4 } & Improve students' course participation & 3 & {$[46]$} \\
\cline { 2 - 4 } Helpful for knowledge integration and internalization & 1 & {$[40]$} \\
\hline \multirow{3}{*}{$\begin{array}{c}\text { Help students communicate with course contents in the classroom } \\
\text { learning }\end{array}$} & Improve communication between teachers and students & 1 & {$[39]$} \\
\cline { 2 - 4 } & Increase graphic competencies and spatial skills & 2 & {$[37]$} \\
\cline { 2 - 4 } & Great potential to be applied in construction projects & 1 & {$[47]$} \\
\cline { 2 - 4 } & Helpful instructional techniques to learn structural analysis & 1 & {$[49]$} \\
\cline { 2 - 4 } & Improve students' understanding of building roof components & 1 & {$[50]$} \\
\cline { 2 - 4 } & Help students to expand their thinking in building-design processes & 1 & {$[17]$} \\
\cline { 2 - 4 } & Improve the clarity of students' 3D perception & 1 & {$[37]$} \\
\hline
\end{tabular}




\subsubsection{Adopting Teaching Methods That Emphasize Locations and Roles}

Teaching methods that emphasize locations, as well as roles, can be adopted in order to create a superior reality learning environment with a diversified learning method. The experimental design method, and the questionnaire and qualitative research methods can be utilized. AR used in ACE education is extremely uniform in teaching methods. Most papers adopted methods that "emphasize the task", and few papers adopted ones that "emphasized the roles" and "emphasize the locations". In other words, how and to what level a student solves tasks in an AR scene needs to be supervised as a way to evaluate learning and systems in fixed locations, such as classrooms or workshops, where they complete a certain learning task. Although on-location learning can more effectively make use of students' prior knowledge, as well as increase their learning interest [51,52], relatively few brought students to real environments for reality learning. The ideal educational tool should also incorporate the authentic experience of on-location learning [53]. Future studies are recommended to adopt AR teaching methods that emphasize the locations. By combining the teaching method with real-life examples of the practices involved, classroom quality can be improved, and the gap between academics and practices can be reduced.

\subsubsection{Providing Learning Strategies with Objective Grading Standards}

Courses with objective grading standards should be given priority in AR experimental courses, such as architectural history and theory, and environment technology. The goal is to be able to meticulously investigate the influence of AR on students' learning outcomes and ultimately improve classroom quality. Adopting a uniform grading standard is difficult for design-related courses [54]. Teachers in such courses face challenges in determining whether a student's logical thinking and aesthetic ability have been enhanced after using AR [17]. Educational institutions and course-grading standards are crucial to such studies because only by standardizing grading can students' learning outcomes be effectively measured [55]. Consequently, it is recommended that future AR courses formulate assessment criteria that are as clear as possible, or directly choose courses that have existing and clear assessment criteria, such as environment technology, and architectural history and theory. In the above-mentioned ways, applying AR in classrooms can be better evaluated, and the quality of pedagogy can be enhanced.

\subsection{Preparing for Challenges}

The challenges of using AR in ACE education are two-fold: Curricula and systems. The former are usually related to the content, form, and timing of courses. The latter are usually associated with the design, manipulation, equipment, and functions of an AR system. Most papers noted that students reported that the time for AR operations is too short or the content of the course is too great $[17,24,46]$ (Table 4). However, Sánchez et al. [35] proposed that students should not spend too much time learning AR; otherwise, learning difficulty will be increased. AR course design requires careful planning and distribution of time in AR operations, which is neither too short nor too long. Discussions are more diffused in system problems, which will be solved as technology advances, such as the difficulty in creating AR models, the small size of AR device screens, and the low level of system stability [35,47]. 
Table 4. AR challenges in ACE education.

\begin{tabular}{|c|c|c|c|}
\hline Inductive Categories & Sub-Categories & Quantity & Sample Research \\
\hline \multirow{4}{*}{ Systems } & Difficult to create AR model or contents & 2 & [47] \\
\hline & Small and not immersive AR device screen & 1 & [35] \\
\hline & Lack of system stability & 1 & [24] \\
\hline & $\begin{array}{l}\text { Tired easily after extended holding marker-based AR } \\
\text { mobile device in the air while sliding it }\end{array}$ & 1 & [49] \\
\hline \multirow{5}{*}{ Curriculums } & Insufficient study time or too much course content & 5 & [46] \\
\hline & $\begin{array}{l}\text { May increase students' learning difficulty after using } \\
\text { AR for a long period of time }\end{array}$ & 1 & [35] \\
\hline & $\begin{array}{l}\text { Can be difficult in design-concept assessment } \\
\text { compared to using AR in a paper-based approach }\end{array}$ & 1 & [17] \\
\hline & $\begin{array}{l}\text { Difficulty in working simultaneously with } \mathrm{AR} \text { and } \\
\text { concentrating on the lecture }\end{array}$ & 1 & [36] \\
\hline & $\begin{array}{l}\text { More effective in a 3D physical model than an } \mathrm{AR} \\
\text { model in helping students to understand the } \\
\text { transformation from } 2 \mathrm{D} \text { images to } 3 \mathrm{D} \text { objects }\end{array}$ & 1 & [29] \\
\hline
\end{tabular}

\subsubsection{Providing a Reasonable Arrangement of Introduction and Operation}

As previously mentioned, the challenge encountered in research from students' feedback is the problem of inadequate time for students to operate AR and that the course content is excessive [17,24]. However, students are not supposed to use AR for too long, as it can increase the difficulty in learning [35]. Cheng et al. [56] suggested that students might experience cognitive overload in an AR learning environment due to task complexity. An adequate understanding and good preparation for the course content are requisite in the initial phase of course design. A reasonable arrangement concerning when to introduce AR and the duration of its use can assist to integrate AR into the classroom more seamlessly and effectively. It is believed that the quality of the course will then be improved.

\subsubsection{Be Aware of Difficulty in Creating AR Contents}

Another challenge is related to system development. The most commonly mentioned problem was the difficulty in creating AR content. Fortunately, many simple AR development tools are available, such as ARKit ${ }^{\circledR}$ and ARCore ${ }^{\circledR}$. It is reasonable to believe that this issue will soon be resolved by providing an efficient software interface to create 3D models, code AR SDK, and design interfaces. In addition, some studies reported that, due to the complex design of the system, students tend to abuse some of the system functions, and therefore are unable to complete the learning tasks [17]. In light of this, the design of the system should be as simple as possible and free of cumbersome and superfluous functions, so that teaching contents can be delivered in a more direct manner. A simpler system design can also enhance system stability to some extent. It is clear that no effort should solely focus on enriching the functions of AR systems because it may distract students.

\subsection{Developing Markerless Systems and Smartphone-Based AR}

Suitable types of AR systems should be selected based on course content, prior to the design and development of the system. It is recommended to develop markerless systems for a larger application range to benefit students with additional convenience. Systems can be accompanied by functions, such as instant online assessments, synchronized assessments, and exchange capabilities to help students to learn what has been taught and develop their critical thinking ability.

The development programs of AR systems are discussed based on three categories: The AR development tool, the AR type, and the AR teaching device. Most of the ACE education research uses open source tools to create AR systems, such as AR-media ${ }^{T M}$, ARToolKit ${ }^{\circledR}$, and Junaio ${ }^{\circledR}$. The most selective AR type is the marker-based AR, with less options in developing markerless AR. It is worth 
noting that marker-based AR systems require students to maintain their own position relative to the markers in order to present virtual information. Consequently, students might feel fatigued after long operating hours [49]. Similar problems have also been noted in architectural practice. For example, due to the complexity of construction sites, it can be difficult to place AR markers properly, and system recognition issues frequently occur [57]. Future research and development should focus on using markerless AR programs, since markerless AR is considered to be more interactive than marker-based AR $[8,12]$. In summary, both the design and arrangement of the marker are crucial in marker-based AR systems, with problems related to the limitations of distance, environment, and movement (Table 5). Researchers can select suitable types of systems for future AR development.

Table 5. Limitations of marker-based AR.

\begin{tabular}{cc}
\hline Type & Description \\
Distance & $\begin{array}{c}\text { The distance between a marker and a device's camera is restricted. Tracking and } \\
\text { positioning of the AR system cannot be performed when the marker is out of the camera's } \\
\text { range, and appears very small or unidentifiable. }\end{array}$ \\
\hline Environment & $\begin{array}{c}\text { The design and affixation of a marker are subject to environmental limitations. Markers } \\
\text { can hardly be affixed in complicated environments, such as construction sites, waterfronts, } \\
\text { and parks. Environmental aesthetics can be violated by on-site marks. }\end{array}$ \\
\hline Movement & $\begin{array}{c}\text { User movements can be limited, since marker-based AR requires the device camera to scan } \\
\text { the marker, and retain an orientation or pace for the best virtual information display. }\end{array}$ \\
\hline
\end{tabular}

Scholars in the field of architectural engineering have reported that tablet computers and wearable devices are superior AR devices to smartphones, and will therefore have great potential as hand-held AR devices [58]. However, smartphones continue to be the most commonly used devices in ACE education currently. This seems to be a reasonable finding, as smartphones are used ubiquitously by today's university students. Compared to other devices, smartphone-based AR can be more convenient for immediate responses to various occasions [59].

\subsection{Combining AR and BIM}

AR has been widely applied in military, education, manufacturing, medical, gaming, maintenance, advertising, and even tourism fields. It is also applied to architecture, in which history, construction, structure, planning, computer graphics, and other topics are also involved. As a result, it might be useful to narrow the scope with more focused studies in architecture. We found that general and domain-specific courses may share a knowledge model of BIM that is currently widely applied. Identifying and considering this core value can help to organize and address pedagogical and technical concerns.

To elucidate the trend of applying AR and what are the courses in which AR is used more frequently, domain-specific courses have revealed a strong connection to the operations and knowledge of the property and configuration of building-related components. The design, construction method, structure analysis, assembly, and estimation have created a life-cycle perspective of construction that is also a complicated system. BIM associates architectural components from level of development or detail (LOD) 100 to 500 with attributes and physical dimensions designated in design, construction, fabrication, and management for quality control or cost estimation. The level of development or detail (LOD) 100 to 500 refers to the stages of concept design (100), schematic design (200), detailed design (300), construction documentation (350), fabrication and assembly (400), and as-built (500), respectively $[60,61]$. The operational subject of AR has contents described under the category of BIM. A great similarity exists with it concerning how AR works on subjects. However, few studies have combined BIM with AR in ACE education. A possible reason for this is that universities are unable to provide students with a working environment that allows actual operation, and therefore 
BIM is used more frequently as a 3D modeling tool in teaching, but not for joint applications with other technologies.

\section{Conclusions}

One of the most important issues of this study is the inclusion of "education" as a keyword to meet the scope of this review. Engineering features, such as mechanics, which will surely be included in an "engineering" search, may find very limited papers along with the search of "education." Cross-domain studies can be found in the sub-fields of architecture, ACE, different university departments, or even professional practices. However, the numbers after the cross-domain search were refined to include pedagogy, which concerns teaching methods and learning strategy. In the future, cross-domain applications that originated from novel fields should also be explored from a pedagogical point of view to accelerate AR's deployment in academics as a top-down approach. Eventually, the bottom-up pedagogical effort made in universities can be interacted with the approach in two ways.

ACE education is inextricably connected to real-world practice. The application of AR technology can help to establish a link between virtual and real-world information for students. This is a critical and effective contribution. Studies have increased annually, many of which have indicated that AR possesses immense application potential. Nevertheless, some problems persist and are worthy of our attention, such as the selection of system types and devices, the application of research methods, and appropriate learning strategies and teaching methods.

AR needs to involve collaborative efforts from different fields. An integrated learning environment is requisite for related-courses, students, instructors, laboratories, and departments. With AR systems, which used to be prepared by computer specialists, it can be difficult for instructors to create AR contents with only an ACE or education background. Creating an AR system includes a series of preparatory works, from creating 3D models, defining interrelationships between modeling components, format conversion, host AR device adaption, and designing interfaces. System design comprises a thorough consideration of interfaces and a time-consuming effort in creating 3D models. Every part of a system contributes to classroom efficiency and effectiveness, and should be thoroughly planned in advance. It is often easier to use off-the-shelf AR tools with lower entry requirements. This issue will soon be extended to course customization and periodic version updates. Courses with laboratory support are superior because the efficiency of research and pedagogy can be integrated. An instructor can also update the course with sufficient software and hardware support. It is certainly more difficult to prepare from the beginning using SDK or by instructors alone.

Collaboration should occur among different roles. Students from different departments may present various knowledge and learning specialties. For example, a student with an ACE background may have to expend more effort to make the best of an AR system, although it might be easier to build models because the subject used is embedded in department courses. Representation of physical objects, however, remains a skill that has to be learned or be familiar to computer experts. Instructors will clearly face more challenges in preparing AR-supported courses. Not only does the delivered course media have to be 3D-modeled, but also the interrelation in between has to be defined, not just in text, but also in a scenario created through a proper computer interface with buttons for selective display or instructions. ACE expert knowledge should also be represented for pedagogy purposes.

The trends and research in AR studies in ACE education have become an integration and collaboration issue, which should be conducted interactively with pedagogical findings, and hopefully with resources integrated across university departments, laboratories, professional training centers, research centers, system providers, and firms with real projects outside of campus.

Author Contributions: Conceptualization, methodology, formal analysis, and resources were made by both authors. Data curation and writing — original draft preparation was made by P.-H.D. Writing—review and editing, supervision, and project administration was made by N.-J.S.

Funding: This research received no external funding.

Conflicts of Interest: The authors declare no conflict of interest. 


\section{Appendix A}

1. Abdullah, F.; Kassim, M.H.B.; Sanusi, A.N.Z. Go virtual: Exploring augmented reality application in representation of steel architectural construction for the enhancement of architecture education. Adv. Sci. Lett. 2017, 23, 804-808. doi:10.1166/asl.2017.7449.

2. Ayer, S.K.; Messner, J.I.; Anumba, C.J. Augmented Reality Gaming in Sustainable Design Education. J. Archit. Eng. 2016, 22. doi:10.1061/(ASCE)AE.1943-5568.0000195.

3. Behzadan, A.H.; Kamat, V.R. Enabling discovery-based learning in construction using telepresent augmented reality. Autom. Constr. 2013, 33, 3-10. doi:10.1016/j.autcon.2012.09.003.

4. Chen, Y.-C.; Chi, H.-L.; Hung, W.-H.; Kang, S.-C. Use of tangible and augmented reality models in engineering graphics courses. J. Prof. Issues Eng. Educ. Pract. 2011, 137, 267-276. doi:10.1061/(ASCE)EI.1943-5541.0000078.

5. Chu, H.-C.; Chen, J.-M.; Hwang, G.-J.; Chen, T.-W. Effects of formative assessment in an augmented reality approach to conducting ubiquitous learning activities for architecture courses. Univers. Access Inf. Soc. 2017, 1-10. doi:10.1007/s10209-017-0588-y.

6. Fonseca, D.; Martí, N.; Redondo, E.; Navarro, I.; Sánchez, A. Relationship between student profile, tool use, participation, and academic performance with the use of Augmented Reality technology for visualized architecture models. Comput. Hum. Behav. 2014, 31, 434-445. doi:10.1016/j.chb.2013.03.006.

7. Fonseca, D.; Redondo, E.; Villagrasa, S. Mixed-methods research: A new approach to evaluating the motivation and satisfaction of university students using advanced visual technologies. Univers. Access Inf. Soc. 2105, 14, 311-332. doi:10.1007/s10209-014-0361-4.

8. Fonseca, D.; Redondo, E.; Valls, F. Motivation and academic improvement using augmented reality for 3D architectural visualization. Educ. Knowl. Soc. (EKS) 2016, 17, 45-64. doi:10.14201/eks20161714564.

9. González, N.A.A. Development of spatial skills with virtual reality and augmented reality. Int. J. Interact. Des. Manuf. (IJIDeM) 2018, 12, 133-144. doi:10.1007/s12008-017-0388-x.

10. Navarro, I.; Fonseca, D. New visualization technologies to improve the representation of architecture in education. Archit. City Environ. 2017, 12, 219-238. doi:10.5821/ace.12.34.5290.

11. Redondo, E.; Sánchez, A.; Moya, J.; Regot, J. The city as a digital classroom. Teaching urbanism and architecture through mobile learning and augmented reality technologies. Feasibility and study case. Archit. City Environ. 2012, 7, 27-54. doi:10.5821/ace.v7i19.2560.

12. Redondo, E.; Fonseca, D.; Sánchez, A.; Navarro, I. Mobile learning in the field of Architecture and Building Construction. A case study analysis. Int. J. Educ. Technol. Higher Educ. 2014, 11, 152-174. doi:10.7238/rusc.v11i1.1844.

13. Redondo, E.; Sánchez, A.; Fonseca, D.; Navarro, I. Geo-Elearning for urbanprojects. New educational strategies using mobile devices. A case study ofeducational research. Archit. City Environ. 2014, 8, 100-132. doi:10.5821/ace.8.24.2714.

14. Sánchez, A.; Redondo, E.; Fonseca, D. Geo-located teaching using handheld augmented reality: Good practices to improve the motivation and qualifications of architecture students. Univers. Access Inf. Soc. 2015, 14, 363-374. doi:10.1007/s10209-014-0362-3.

15. Shanbari, H.; Blinn, N.; Issa, R.R.A. Using augmented reality video in enhancing masonry and roof component comprehension for construction management students. Eng. Constr. Archit. Manag. 2016, 23, 765-781. doi:10.1108/ECAM-01-2016-0028.

16. Shirazi, A.; Behzadan, A.H. Design and assessment of a mobile augmented reality-based information delivery tool for construction and civil engineering curriculum. J. Prof. Issues Eng. Educ. Pract. 2015, 141. doi:10.1061/(ASCE)EI.1943-5541.0000229.

17. Shirazi, A.; Behzadan, A.H. Content delivery using augmented reality to enhance student's performance in a building design and assembly project. Adv. Eng. Educ. 2015, 4. 1-24. 
18. Turkan, Y.; Radkowski, R.; Karabulut-Ilgu, A.; Behzadan, A.H.; Chen, A. Mobile augmented reality for teaching structural analysis. Adv. Eng. Inf. 2017, 34, 90-100. doi:10.1016/j.aei.2017.09.005.

19. Uribe, F.C. Increased reality applied to the teaching of the descriptive geometry. AUS 2015, 18, 18-22. doi:10.4206/aus.2015.n18-04.

20. Vassigh, S.; Davis, D.; Behzadan, A.H.; Mostafavi, A.; Rashid, K.; Alhaffar, H.; Elias, A.; Gallardo, G. Teaching Building Sciences in Immersive Environments: A Prototype Design, Implementation, and Assessment. Int. J. Constr. Educ. Res. 2018, doi:10.1080/15578771.2018.1525445.

21. Wang, T.-K.; Huang, J.; Liao, P.-C.; Piao, Y. Does Augmented Reality Effectively Foster Visual Learning Process in Construction? An Eye-Tracking Study in Steel Installation, Adv. Civ. Eng. 2018, 12. doi:10.1155/2018/2472167.

\section{References}

1. Milgram, P.; Takemura, H.; Utsumi, A.; Kishino, F. Augmented reality: A class of displays on the reality-virtuality continuum. In Proceedings of the Telemanipulator and Telepresence Technologies, Boston, MA, USA, 31 October-1 November 1994; Volume 2351, pp. 282-292. [CrossRef]

2. Azuma, R.T. A survey of augmented reality. Presence-Teleoper. Virtual Environ. 1997, 6, 355-385. [CrossRef]

3. Azuma, R.; Baillot, Y.; Behringer, R.; Feiner, S.; Julier, S.; MacIntyre, B. Recent advances in augmented reality. IEEE Comput. Graphics Appl. 2001, 21, 34-47. [CrossRef]

4. Irizarry, J.; Gheisari, M.; Williams, G.; Walker, B.N. Infospot: A mobile augmented reality method for accessing building information through a situation awareness approach. Autom. Constr. 2013, 33, 11-23. [CrossRef]

5. Hou, L.; Wang, X.; Bernold, L.; Love Peter, E.D. Using animated augmented reality to cognitively guide assembly. J. Comput. Civil Eng. 2013, 27, 439-451. [CrossRef]

6. Koch, C.; Neges, M.; König, M.; Abramovici, M. Natural markers for augmented reality-based indoor navigation and facility maintenance. Autom. Constr. 2014, 48, 18-30. [CrossRef]

7. Meža, S.; Turk, Ž.; Dolenc, M. Measuring the potential of augmented reality in civil engineering. Adv. Eng. Software 2015, 90, 1-10. [CrossRef]

8. Chi, H.-L.; Kang, S.-C.; Wang, X. Research trends and opportunities of augmented reality applications in architecture, engineering, and construction. Autom. Constr. 2013, 33, 116-122. [CrossRef]

9. Vanlande, R.; Nicolle, C.; Cruz, C. IFC and building lifecycle management. Autom. Constr. 2008, 18, 70-78. [CrossRef]

10. Hartmann, T.; Gao, J.; Fischer, M. Areas of Application for 3D and 4D Models on Construction Projects. J. Constr. Eng. Manag. 2008, 134, 776-785. [CrossRef]

11. Park, C.-S.; Lee, D.-Y.; Kwon, O.-S.; Wang, X. A framework for proactive construction defect management using BIM, augmented reality and ontology-based data collection template. Autom. Constr. 2013, 33, 61-71. [CrossRef]

12. Utaberta, N.; Hassanpour, B.; Bahar, M.A. An evaluation of criteria-based assessment and grading in architecture design. Res. J. Appl. Sci. Eng. Technol. 2013, 5, 346-352. [CrossRef]

13. Meža, S.; Turk, Ž.; Dolenc, M. Component based engineering of a mobile BIM-based augmented reality system. Autom. Constr. 2014, 42, 1-12. [CrossRef]

14. Kaufmann, H.; Schmalstieg, D.; Wagner, M. Construct3d: A virtual reality application for mathematics and geometry education. Educ. Inf. Technol. 2000, 5, 263-276. [CrossRef]

15. Kaufmann, H.; Schmalstieg, D. Mathematics and geometry education with collaborative augmented reality. Comput. Graphics 2003, 27, 339-345. [CrossRef]

16. Billinghurst, M. Augmented reality in education. New Horizons Learn. 2003, 12 . Available online: http://www.durhamnc.gov/agendas_new/2015/cm20150302/10290_CONTRACT_E202_CONTRACT_ ATTACHMENT_365760_627078.PDF (accessed on 3 May 2019).

17. Ayer, S.K.; Messner, J.I.; Anumba, C.J. Augmented reality gaming in sustainable design education. J. Archit. Eng. 2016, 22, 04015012. [CrossRef] 
18. Ibrahim, A.; Huynh, B.; Downey, J.; Höllerer, T.; Chun, D.; donovan, J.O. Arbis pictus: A study of vocabulary learning with augmented reality. IEEE Trans. Visual Comput. Graphics 2018, 24, 2867-2874. [CrossRef] [PubMed]

19. Akçayır, M.; Akçayır, G. Advantages and challenges associated with augmented reality for education: A systematic review of the literature. Educ. Res. Rev. 2017, 20,1-11. [CrossRef]

20. Yilmaz, R.M. Educational magic toys developed with augmented reality technology for early childhood education. Comput. Hum. Behav. 2016, 54, 240-248. [CrossRef]

21. Martín-Gutiérrez, J.; Fabiani, P.; Benesova, W.; Meneses, M.D.; Mora, C.E. Augmented reality to promote collaborative and autonomous learning in higher education. Comput. Hum. Behav. 2015, 51, 752-761. [CrossRef]

22. Cai, S.; Wang, X.; Chiang, F.-K. A case study of augmented reality simulation system application in a chemistry course. Comput. Hum. Behav. 2014, 37, 31-40. [CrossRef]

23. Wang, T.-K.; Huang, J.; Liao, P.-C.; Piao, Y. Does augmented reality effectively foster visual learning process in construction? An eye-tracking study in steel installation. Adv. Civ. Eng. 2018, 12. [CrossRef]

24. Fonseca, D.; Redondo, E.; Villagrasa, S. Mixed-methods research: A new approach to evaluating the motivation and satisfaction of university students using advanced visual technologies. Univers. Access Inf. Soc. 2015, 14, 311-332. [CrossRef]

25. Redondo, E.; Fonseca, D.; Sánchez, A.; Navarro, I. Mobile learning in the field of Architecture and Building Construction. A case study analysis. Int. J. Educ. Technol. Higher Educ. 2014, 11, 152-174. [CrossRef]

26. Glasser, D.E. Reflections on Architectural Education. J. Archit. Educ. 2000, 53, 250-252. [CrossRef]

27. Wang, X.; Kim, M.J.; Love, P.E.D.; Kang, S.-C. Augmented Reality in built environment: Classification and implications for future research. Autom. Constr. 2013, 32, 1-13. [CrossRef]

28. Behzadan, A.H.; Kamat, V.R. Enabling discovery-based learning in construction using telepresent augmented reality. Autom. Constr. 2013, 33, 3-10. [CrossRef]

29. Chen, Y.-C.; Chi, H.-L.; Hung, W.-H.; Kang, S.-C. Use of tangible and augmented reality models in engineering graphics courses. J. Prof. Issues Eng. Educ. Pract. 2011, 137, 267-276. [CrossRef]

30. Kamarainen, A.M.; Met alalf, S.; Grotzer, T.; Browne, A.; Mazzuca, D.; Tutwiler, M.S.; Dede, C.; et al. EcoMOBILE: Integrating augmented reality and probeware with environmental education field trips. Comput. Educ. 2013, 68, 545-556. [CrossRef]

31. Huberman, M.; Miles, M.B. The Qualitative Researcher's Companion; Sage: Thousand Oaks, CA, USA, 2002.

32. Hwang, G.-J.; Tsai, C.-C. Research trends in mobile and ubiquitous learning: a review of publications in selected journals from 2001 to 2010. Br. J. Educ. Technol. 2011, 42, E65-E70. [CrossRef]

33. Palmarini, R.; Erkoyuncu, J.A.; Roy, R.; Torabmostaedi, H. A systematic review of augmented reality applications in maintenance. Rob. Comput. Integr. Manuf. 2018, 49, 215-228. [CrossRef]

34. Johnson, B.; Christensen, L. Educational Research: Quantitative and Qualitative Approaches; Allyn \& Bacon: Boston, MA, USA, 2000.

35. Sánchez, A.; Redondo, E.; Fonseca, D. Geo-located teaching using handheld augmented reality: Good practices to improve the motivation and qualifications of architecture students. Univers. Access Inf. Soc. 2015, 14, 363-374. [CrossRef]

36. Shirazi, A.; Behzadan, A.H. Design and assessment of a mobile augmented reality-based information delivery tool for construction and civil engineering curriculum. J. Prof. Issues Eng. Educ. Pract. 2015, 141, 04014012. [CrossRef]

37. Uribe, F.C. Increased reality applied to the teaching of the descriptive geometry. AUS 2015, 18, 18-22. [CrossRef]

38. González, N.A.A. Development of spatial skills with virtual reality and augmented reality. Int. J. Interact. Des. Manuf. (IJIDeM) 2018, 12, 133-144. [CrossRef]

39. Shirazi, A.; Behzadan, A.H. Content delivery using augmented reality to enhance student's performance in a building design and assembly project. Adv. Eng. Educ. 2015, 4, 1-24.

40. Chu, H.-C.; Chen, J.-M.; Hwang, G.-J.; Chen, T.-W. Effects of formative assessment in an augmented reality approach to conducting ubiquitous learning activities for architecture courses. Univers. Access Inf. Soc. 2017, 1-10. [CrossRef]

41. Redondo, E.; Sánchez, A.; Fonseca, D.; Navarro, I. Geo-Elearning for urbanprojects. New educational strategies using mobile devices. A case study ofeducational research. Archit. City Environ. 2014, 8, 100-132. [CrossRef] 
42. Wu, H.-K.; Lee, S.W.-Y.; Chang, H.-Y.; Liang, J.-C. Current status, opportunities and challenges of augmented reality in education. Comput. Educ. 2013, 62, 41-49. [CrossRef]

43. Redondo, E.; Sánchez, A.; Moya, J.; Regot, J. The city as a digital classroom. Teaching urbanism and architecture through mobile learning and augmented reality technologies. Feasibility and study case. Archit. City Environ. 2012, 7, 27-54. [CrossRef]

44. Fonseca, D.; Redondo, E.; Valls, F. Motivation and academic improvement using augmented reality for 3D architectural visualization. Educ. Knowl. Soc. (EKS) 2016, 17, 45-64. [CrossRef]

45. Lai, C.-L.; Hwang, G.-J. High school teacher's perspectives on applying different mobile learning strategies to science courses: The national mobile learning program in taiwan. Int. J. Mob. Learn. Organ. 2015, 9, 124-145. [CrossRef]

46. Navarro, I.; Fonseca, D. New visualization technologies to improve the representation of architecture in education. Archit. City Environ. 2017, 12, 219-238. [CrossRef]

47. Fonseca, D.; Martí, N.; Redondo, E.; Navarro, I.; Sánchez, A. Relationship between student profile, tool use, participation, and academic performance with the use of Augmented Reality technology for visualized architecture models. Comput. Hum. Behav. 2014, 31, 434-445. [CrossRef]

48. Abdullah, F.; Kassim, M.H.B.; Sanusi, A.N.Z. Go virtual: Exploring augmented reality application in representation of steel architectural construction for the enhancement of architecture education. Adv. Sci. Lett. 2017, 23, 804-808. [CrossRef]

49. Turkan, Y.; Radkowski, R.; Karabulut-Ilgu, A.; Behzadan, A.H.; Chen, A. Mobile augmented reality for teaching structural analysis. Adv. Eng. Inf. 2017, 34, 90-100. [CrossRef]

50. Shanbari, H.; Blinn, N.; Issa, R.R.A. Using augmented reality video in enhancing masonry and roof component comprehension for construction management students. Eng. Constr. Archit. Manag. 2016, 23, 765-781. [CrossRef]

51. Squire, K.; Klopfer, E. Augmented Reality Simulations on Handheld Computers. J. Learn. Sci. 2007, 16, 371-413. [CrossRef]

52. Klopfer, E.; Squire, K. Environmental Detectives-The development of an augmented reality platform for environmental simulations. Educ. Technol. Res. Dev. 2008, 56, 203-228. [CrossRef]

53. Rosenbaum, E.; Klopfer, E.; Perry, J. On Location Learning: Authentic Applied Science with Networked Augmented Realities. J. Sci. Educ. Technol. 2007, 16, 31-45. [CrossRef]

54. Hassanpour, B.; Utaberta, N.; Tahir, M.M.; Abdullah, N.A.G.; Spalie, N.; Che-Ani, A.I. Developing sustainable approach in architectural education: Lesson from critique session experience of architecture studio program. In Proceedings of the Ninth WSEAS International Conference on Education and Educational Technology (EDU'10), Iwate Prefecture University, Japan, 4-6 October 2010; pp. 325-331.

55. Cheng, K.-H.; Tsai, C.-C. Affordances of Augmented Reality in Science Learning: Suggestions for Future Research. J. Sci. Educ. Technol. 2013, 22, 449-462. [CrossRef]

56. Zhou, Y.; Luo, H.; Yang, Y. Implementation of augmented reality for segment displacement inspection during tunneling construction. Autom. Constr. 2017, 82, 112-121. [CrossRef]

57. Kwon, O.-S.; Park, C.-S.; Lim, C.-R. A defect management system for reinforced concrete work utilizing BIM, image-matching and augmented reality. Autom. Constr. 2014, 46, 74-81. [CrossRef]

58. Carmigniani, J.; Furht, B.; Anisetti, M.; Ceravolo, P.; Damiani, E.; Ivkovic, M. Augmented reality technologies, systems and applications. Multimedia Tools Appl. 2011, 51, 341-377. [CrossRef]

59. Diao, P.-H.; Shih, N.-J. MARINS: A Mobile Smartphone AR System for Pathfinding in a Dark Environment. Sensors 2018, 18, 3442. [CrossRef]

60. AIA. AIA Document E202-2008: Building Information Modeling Protocol Exhibit. AIA Contract Document Series E202, Washington, DC. 2008; p. 9. Available online: http://www.durhamnc.gov/agendas_new/2015/ cm20150302/10290_CONTRACT_E202_CONTRACT_ATTACHMENT_365760_627078.PDF (accessed on 3 May 2019).

61. Leite, F.; Akcamete, A.; Akinci, B.; Atasoy, G.; Kiziltas, S. Analysis of modeling effort and impact of different levels of detail in building information models. Autom. Constr. 2011, 20, 601-609. [CrossRef]

(C) 2019 by the authors. Licensee MDPI, Basel, Switzerland. This article is an open access article distributed under the terms and conditions of the Creative Commons Attribution (CC BY) license (http://creativecommons.org/licenses/by/4.0/). 